\title{
Effect of Acetic Acid and Sodium Bicarbonate Supplemented to Drinking Water on Water Quality, Growth Performance, Organ Weights, Cecal Traits and Hematological Parameters of Young Broilers
}

\author{
Yordan Martínez ${ }^{1, * \mathbb{D}}$, Cristopher Isaac Almendares ${ }^{1}$, Cristhian José Hernández ${ }^{1}$, Mavir Carolina Avellaneda ${ }^{2} \mathbb{D}$, \\ Ana Melissa Urquía ${ }^{3}$ and Manuel Valdivié ${ }^{4}$
}

check for updates

Citation: Martínez, Y.; Almendares, C.I.; Hernández, C.J.; Avellaneda, M.C.; Urquía, A.M.; Valdivié, M. Effect of Acetic Acid and Sodium Bicarbonate Supplemented to Drinking Water on Water Quality, Growth Performance, Organ Weights, Cecal Traits and Hematological Parameters of Young Broilers. Animals 2021, 11, 1865.

https://doi.org/10.3390/ani11071865

Academic Editor: Velmurugu Ravindran

Received: 7 May 2021

Accepted: 8 June 2021

Published: 23 June 2021

Publisher's Note: MDPI stays neutral with regard to jurisdictional claims in published maps and institutional affiliations.

Copyright: (c) 2020 by the authors. Licensee MDPI, Basel, Switzerland. This article is an open access article distributed under the terms and conditions of the Creative Commons Attribution (CC BY) license (https:/ / creativecommons.org/licenses/by/ $4.0 /)$.
1 Poultry Research and Teaching Center, Agricultural Science and Production Department, Zamorano University, P.O. Box 93, San Antonio de Oriente 11101, Honduras; cristopher.almendare.2020@alumni.zamorano.edu (C.I.A.); cristhian.hernandez.2020@alumni.zamorano.edu (C.J.H.)

2 Plant Pathology, Diagnosis and Molecular Research Lab, Agricultural Sciences and Production Department, Zamorano University, P.O. Box 93, San Antonio de Oriente 11101, Honduras; cavellaneda@zamorano.edu

3 Environment and Development Department, Zamorano University, P.O. Box 93,

San Antonio de Oriente 11101, Honduras; aurquia@zamorano.edu

4 National Center for Laboratory Animal Production, P.O. Box 6240, Santiago de las Vegas, Rancho Boyeros 10100, La Habana, Cuba; mvaldivie@ica.co.cu

* Correspondence: ymartinez@zamorano.edu; Tel.: +504-94422496

Simple Summary: Currently, many poultry productions supply drinking water extracted from wells or other sources whose physical, chemical and microbiological characteristics are sometimes unknown, especially $\mathrm{pH}$ and its impact on production and health of the birds during their productive life. The following study evaluated the effect of an acidifier (acetic acid $0.4 \%$; T1), an apparently neutral $\mathrm{pH}$ (T2) and the use of an alkalizing (sodium bicarbonate 1\%; T3) in drinking water on growth of broilers during their first 10 days of life. T3 changed the normal parameters of drinking water for the broilers, and this treatment also provoked high mortality, ascites and poor productive development, and it modified the relative weight of the immune organs, liver, heart and pancreas, as well as the cecal $\mathrm{pH}$, although cecal lactic acid bacteria count and hematological indicators were unchanged. Likewise, it is contradictory that $\mathrm{T} 1 \mathrm{did}$ not show improvements in performance and cecal traits compared to drinking water with an apparently neutral $\mathrm{pH}$. Therefore, the supply of alkaline water (due to high Na content) affects the performance, health, immunity and digestive physiology of broilers, which shows that the control of this parameter in drinking water has a direct impact on animal growth and the economy of the poultry producer.

Abstract: To evaluate the effect of acetic acid and sodium bicarbonate supplemented to drinking water on water quality, growth performance, relative organ weights, cecal traits and hematological parameters of broilers, a total of 456 one-day-old Cobb MV $\times$ Cobb 500 FF mixed broilers were randomly placed in three experimental treatments, with four replicates per treatment and 38 birds per replicate, for 10 days. The treatments consisted of the use of acetic acid $(0.4 \%$; T1) as acidifier, an apparently neutral $\mathrm{pH}$ (T2) and sodium bicarbonate (1\%; T3) as alkalizer of the drinking water. T3 showed the highest values $(p<0.05)$ for total dissolved solids, electrical conductivity, salinity and $\mathrm{pH}$. T1 and T2 showed the same productive response $(p>0.05)$; however, T3 decreased $(p<0.05)$ body weight, feed intake and the relative weight of the pancreas and immune organs and increased $(p<0.05)$ water intake, mortality and relative weight of the heart and liver. Likewise, T3 increased $(p<0.05)$ the cecal $\mathrm{pH}$, although without changes for the cecal lactic cecal bacteria count and blood parameters $(p>0.05)$. The acid $\mathrm{pH}$ of the drinking water had no effect on the biological response of broilers compared to T2; however, the T3 provoked high mortality, ascites, low productivity and abnormal growth of some organs. 
Keywords: blood indicator; broiler; cecal characteristic; visceral and immune organ; water pH

\section{Introduction}

The post-hatching stage of broilers has many critical issues to consider. Throughout their first 10 days of life, broilers undergo a series of critical transitions that affect the way they receive nutrients; therefore, bird care and observation during this period are important for optimal flock performance [1]. Newborn chicks need to consume feed and water immediately after hatching to supply energy requirements and hydrate the body for various metabolic functions, respectively [2]. Therefore, the percentage of broiler viability is higher when the consumption and quality of feed and water is adequately controlled [3].

Approximately $70 \%$ of the total bird weight is water; therefore, broilers should consume at least twice as much water compared to feed, being the main vehicle of the feed bolus in the gastrointestinal tract (GIT) [4]. Therefore, water quality from any source requires exhaustive control, mainly in physical-chemical parameters such as turbidity, electrical conductivity, total dissolved solids, hardness, total chlorine and $\mathrm{pH}$; and biological parameters such as the presence of pathogens, since all of these directly influence water consumption and animal performance. Water $\mathrm{pH}$ has been related to impact on digestive and immune organs and poultry health [5]; thus, Engberg et al. [6] mentioned that the $\mathrm{pH}$ within each segment of the gastrointestinal tract determines the chemical environment and directly influences the digestion and absorption of nutrients. Although the animal organism has the ability to buffer intra and extracellular $\mathrm{pH}$, some results show that the acidic drinking water supplied in the initial stage of fattening broilers reduces $\mathrm{pH}$ in some parts of the gastrointestinal tract, such as the jejunum, ileum and cecum, which promotes a decrease of pathogenic bacteria colonization [7]. Similarly, Hajati [8] mentioned that acidic drinking water provides a second layer of protection against lactic acid bacteria, which allows its establishment as part of the ecology of the enteric system.

Thus, the use of organic acids to lower drinking water $\mathrm{pH}$ is a common practice in many poultry companies, especially in periods of stress; however, the scientific results are inconsistent. In this sense, Bouassi et al. [9] and Açıkgöz et al. [10] reported improvements in growth performance when they used organic acids on drinking water in poultry. However, Hamid et al. [11] and Martinez et al. [12] did not find productive benefits in broilers when acidifying the water with organic acids, and some animals also presented metabolic disturbances. On the other hand, few studies have been developed to know the effect of alkaline drinking water on broiler production, considering that many sources of water used by poultry farms have high Na content [13]. In this sense, Klasing [14] reported that an excess of $\mathrm{Na}$ in the drinking water of broilers causes dehydration, heart failure with edema, ascites and high mortality. The comparative study of different $\mathrm{pHs}$ of drinking water in broilers will allow us to know its direct effect on the digestive system, immune organs, productivity, cecal microflora and possible conditions in the most critical stage (the first 10 days of life) of this poultry category. The present study evaluated the effect of acetic acid and sodium bicarbonate supplemented to drinking water on water quality, growth performance, visceral and immune weight organs, cecal traits and hematological parameters of apparently healthy young broilers.

\section{Materials and Methods}

The Science and Agricultural Production Department at Zamorano University, located in San Antonio de Oriente (Honduras), reviewed and approved all the standardized procedures performed in this experiment, which were conducted under the Guidelines for Experimental Animals (Reference number: 20245 and 20193). 


\subsection{Study Location and Site}

The study was developed at the Poultry Research and Training Center of Zamorano University, located in Valle del Yeguare at km 32 of the Tegucigalpa-Danlí highway, Honduras. The training and research center has an average temperature of $26^{\circ} \mathrm{C}$, at an altitude of $800 \mathrm{~m}$ above sea level, and an annual rainfall of $1100 \mathrm{~mm}$.

\subsection{Animals and Treatments}

A total of 456 one-day-old Cobb MV $\times$ Cobb 500 FF mixed broilers were collected equally, 50\% male and 50\% female from same flock. The broilers were randomly placed in three experimental treatments, four replicates per treatment and 38 birds per replicate, for 10 days. It should be noted that this trial was carried out in the starter phase of broilers (the first 10 days of age), which is considered the most critical productive stage in the growth of these animals [2,15-17]. Additionally, a diet was formulated considering the nutritional requirements of the genetic line under study (Table 1) [18]. The treatments consisted of the use of acetic acid $(0.4 \%$; T1) as acidifier, an apparently neutral $\mathrm{pH}$ (T2) and sodium bicarbonate (1\%; T3) as alkalizer of the drinking water [12]. The allowed limits of water $\mathrm{pH}$ $(6.5-8.5)[5]$ were considered to acidify and alkalize the drinking water supplied to broilers.

Table 1. Ingredients and nutritional contributions of broilers diet (0-10 days).

\begin{tabular}{ll}
\hline Ingredients & Starter (\%) (0-10 Days) \\
\hline Cornmeal & 59.00 \\
Soybean meal & 32.4 \\
Premix of minerals and vitamins ${ }^{1}$ & 0.50 \\
Sodium chloride & 0.35 \\
African palm oil & 3.53 \\
Choline & 0.05 \\
DL-Methionine & 0.34 \\
L-Threonine & 0.16 \\
L-Lysine & 0.32 \\
Calcium carbonate & 1.60 \\
Biofos & 1.53 \\
Mycofix plus 5.0 ${ }^{\circledR}$ & 0.12 \\
Enzymes Lumis Lbzyme X50 ${ }^{\circledR}$ & 0.05 \\
Coccidiostat & 0.05 \\
Nutritional contributions & \\
Metabolizable energy $(\mathrm{kcal} / \mathrm{kg})$ & 2975 \\
Crude protein & 22.00 \\
Neutral fiber detergent & 15.22 \\
Crude fiber & 3.05 \\
Calcium & 0.90 \\
P available & 0.45 \\
Lysine & 1.22 \\
Methionine + Cystine & 0.91 \\
Threonine & 0.83 \\
Tryptophan & 0.20 \\
\hline Ech kg contans vitamn A 11,550IU & \\
\hline
\end{tabular}

${ }^{1}$ Each kg contains vitamin A 11,550 IU, vitamin D3 $4300 \mathrm{IU}$, vitamin E $27.5 \mathrm{IU}$, vitamin K3 $3.85 \mathrm{mg}$, vitamin B1 $2.75 \mathrm{mg}$, vitamin B2 $9.9 \mathrm{mg}$, vitamin B6 $3.85 \mathrm{mg}$, vitamin B12 $22.0 \mathrm{Mcg}$, niacin $49.5 \mathrm{mg}$, pantothenic acid $15.4 \mathrm{mg}$, folic acid $1.38 \mathrm{mg}$, biotin $166 \mathrm{mcg}$; selenium $0.09 \mathrm{mg}$, iodine $0.18 \mathrm{mg}$, copper $3.00 \mathrm{mg}$, iron $36.0 \mathrm{mg}$, manganese $54.0 \mathrm{mg}$, zinc $48.0 \mathrm{mg}$, cobalt $0.12 \mathrm{mg}$.

\subsection{Experimental Conditions}

Each replica consisted of a bed of wooden chip in each pen and with a density of 10 birds $/ \mathrm{m}^{2}$. The supply water was ad libitum using plastic gallon waterers, as was the feed mash in plastic hopper feeders. Temperature and ventilation inside the shed were controlled by gas breeders, curtain handling and fans. The photoperiod distribution was as follows: 0-7 days old, 23 light (L):1 dark (D); 8-10 days, 20 L:4D [18]. The shed was disinfected according to environmental quality standards of Poultry Research and Training 
Center Protocol, $24 \mathrm{~h}$ before the chicks entered the experimental area, this was disinfected with quaternary ammonium (5\%). No medicines or therapeutic veterinary care were used throughout the experimental stage. Birds were vaccinated against Newcastle disease, Gumboro disease and bronchitis on their first day.

\subsection{Drinking Water Quality}

Water quality parameters including temperature $\left({ }^{\circ} \mathrm{C}\right), \mathrm{pH}$, electrical conductivity (EC), total dissolved solids (TDS) and salinity (SALT) were analyzed using a multiparameter meter, model WD-35604-00 (Oakton Electronic, Vernon Hills, IL, USA), with an accuracy of \pm 0.01 at $\mathrm{pH}, \pm 0.5^{\circ} \mathrm{F} / \mathrm{O}$, and $\pm 1 \%$ (full scale) for EC, TDS, and SALT parameters. Additionally, water turbidity was measured using the standardized method of nephelometry with a SperDirect turbidimeter 860040 (Sper scientific, Scottsdale, AZ, USA) with an accuracy of $\pm 5 \%$. Residual chlorine was measured by colorimetry with a CN66-F kit $(\mathrm{HACH}$, Loveland, CO, USA), which has a measuring range of 0.1-3.4 mg/L. Additionally, the presence and/or absence of fecal coliforms was performed by counting on plates using $3 \mathrm{M}^{\mathrm{TM}}$ Petrifilm ${ }^{\mathrm{TM}}$ (3M, Saint Paul, MN, USA). All analyses were done five times.

\subsection{Growth Performance}

The indicators of the broiler's growth performance were determined on a weekly basis. Viability was determined by living animals among those existing at the beginning of the experiment. The feed and water intake were calculated using the offer and reject method. The feed conversion ratio was calculated as the amount of feed ingested, for a gain of $1 \mathrm{~kg}$ of body weight. The initial and final individual weight of each stage was taken using a Navigator OHAUS scale, model N38110, with a precision of $\pm 1 \mathrm{~g}$ (OHAUS $^{\mathrm{TM}}$, Parsippany, NJ, USA).

\subsection{Relative Weight of Digestive and Lymphoid Organs and Intestinal $p H$}

At 10 days old, 20 chicks per treatment with six hours of fasting were selected randomly and weighed individually before slaughter on a Navigator OHAUS model N38110 scale with a precision of $\pm 1 \mathrm{~g}$ (OHAUS ${ }^{\mathrm{TM}}$, Parsippany, NJ, USA). The birds were euthanized using the mechanical cervical dislocation method; the procedure was performed by a certified veterinarian. The following organs were extracted and weighed: immune organs (bursa of Fabricius, spleen and thymus), and digestive organs (cecum, gizzard, proventriculus and small intestine). The organs were weighed using a BLAZE BL scale, model 100-01-BK, with a precision of $\pm 0.01 \mathrm{~g}$ (Dalman Enterprises Ltd., Wycombe, Buckinghamshire, UK). After slaughter, the small intestine and caecum $\mathrm{pH}$ of 10 broilers per treatment were determined by a digital potentiometer Oakton ${ }^{\circledR}$ model 700 digital pH meter (Oakton Instruments, Vermon Hills, IL, USA). Following the manufacturer's recommendations, the potentiometer was calibrated using $\mathrm{pH}$ buffers of 1.68, 4.01, 7.00, 10.01 and 12.45 .

Moreover, the left cecum of five birds per treatment were randomly selected. The mucosa was scraped with a scalpel for microbiological culture. The cecal content of each sample was placed in a sterilized tube, and the weight was recorded and diluted with Butterfield's phosphate buffered dilution water to a 1:9 ratio (weight:volume). The diluted cecal contents were homogenized, and serial dilutions $(1 / 10)$ were made from it until achieving a $10^{5}$ dilution. Aliquots of $0.1 \mathrm{~mL}$ of each dilution were spread onto the surface of a plate with MRS agar (Neogen Acumedia, Lansing, MI, USA) supplemented with methylene blue $(0.016 \mathrm{~g} / 1000 \mathrm{~mL})$ with a $\mathrm{pH}$ of 5.6 , for $48 \mathrm{~h}$ at $37{ }^{\circ} \mathrm{C}$ in anaerobiosis (Gas Pak ${ }^{\mathrm{TM}}$ BBL, Cockeysville, MD, USA). Counts of lactic acid bacteria were reported as $\log 10 \mathrm{CFU} / \mathrm{g}$ by colonies' morphology on MRS + MB agar. Gram stain and catalase activity were tested on each type of the reported colony [19]. A Labomed model LX400 light microscope (Labomed Inc., Los Angeles, CA, USA) was used to characterize bacterial morphology. All the microbiological tests were performed in the Food Microbiology Laboratory of the Zamorano University. 


\subsection{Hemogram}

On day 10, a hematological examination was performed on six fasting broilers per treatment. The blood was removed $(10 \mathrm{~mL})$ by puncture of the left-wing vein and deposited in tubes with anticoagulants. In blood plasma, erythrocytes and leukocytes were determined by automatic counting in a Neubauer Chamber model 68058-15 (Electron, Microscopy, Sciences, Hatfield, PA, USA) using 2B methyl violet as a diluent. Additionally, platelets were quantified in the Neubauer Chamber model 68058-15 (Electron, Microscopy, Sciences, Hatfield, PA, USA) using ammonium oxalate solution. The differential leukocyte formula was determined by peripheral blood smear (PSF), with Wright's stain, and observed in the microscope with a $100 \times$ objective for the differentiation of heterophiles, eosinophils, lymphocytes, monocytes and basophils. The hematocrit-CVP was determined by the capillary microcentrifugation process. Hemoglobin was determined according to the hemotest method. Mean corpuscular volume (MCV) and mean corpuscular hemoglobin $(\mathrm{MCH})$ are determined according to the formulas: $\mathrm{MCV}(\mathrm{fl})=\left(\operatorname{Hct}(\mathrm{L} / \mathrm{L}) / \mathrm{RBC}\left(10^{12} / \mathrm{L}\right)\right) \times 1000$ and $\mathrm{MCH}=\mathrm{Hb}(\mathrm{g} / \mathrm{L}) / \mathrm{RBC}$ (millions $/ \mu \mathrm{L}$ ).

\subsection{Statistical Analysis}

The data was processed using a one-way analysis of variance (ANOVA) in a completely randomized design; before carrying out the analysis of variance, the normality of the data was verified using the Kolmogorov-Smirnov test, and the Bartlett's test was used to evaluate the uniformity of the variance, where necessary. Finally, Duncan's test was used to determine the differences between means $(p<0.05)$. All the analyses were performed using the statistics software SPSS version 23.0 (SPSS Inc., IBM Corporation, New York, NY, USA).

\section{Results}

\subsection{Water Quality}

Table 2 shows the physical, chemical and microbiological characteristics of drinking water for broilers. Throughout the three treatments, $\mathrm{pH}$, electrical conductivity and total dissolved solid count showed significant differences $(p<0.05)$ among each other, whereas salinity in T3 was higher $(p<0.05)$ than in T1 and T2. However, the temperature showed no differences $(p>0.05)$ among treatments. The presence of total and fecal coliforms was not found. In addition, T1 and T3 had no presence of residual chlorine in relation to neutral water.

Table 2. Effect of acetic acid and sodium bicarbonate supplemented to drinking water on its physical, chemical and microbiological characteristics.

\begin{tabular}{cccccc}
\hline \multicolumn{7}{c}{ Experimental Treatments } \\
\hline Items & T1 & T2 & T3 & SEM \pm & $p$-Value \\
\hline Temperature $\left({ }^{\circ} \mathrm{C}\right)$ & 26.37 & 26.33 & 26.27 & 0.033 & 0.178 \\
pH & $4.01^{\mathrm{c}}$ & $7.03^{\mathrm{b}}$ & $8.60^{\mathrm{a}}$ & 0.025 & 0.001 \\
Electrical conductivity (S/cm) & $166.73^{\mathrm{b}}$ & $86.00^{\mathrm{c}}$ & $4850.00^{\mathrm{a}}$ & 30.655 & 0.001 \\
Total dissolved solids (ppm) & $117.67^{\mathrm{b}}$ & $61.20^{\mathrm{c}}$ & $3443.33^{\mathrm{a}}$ & 44.270 & 0.001 \\
Salinity (ppm) & $0.08^{\mathrm{b}}$ & $0.04^{\mathrm{b}}$ & $2.427^{\mathrm{a}}$ & 0.031 & 0.001 \\
Turbidity (NTU) & 0.00 & 0.00 & 0.00 & - & - \\
Residual chlorine (mg/L) & 0.00 & 0.20 & 0.00 & - & - \\
Total coliforms (CFU) & Absence & Absence & - & - & - \\
Fecal coliforms (CFU) & Absence & Absence & - & - & - \\
\hline
\end{tabular}

$\overline{\mathrm{a}, \mathrm{b}, \mathrm{c}}$ Means with different letters in the same row differ at $p<0.05$. SEM: standard error of the mean; CFU: colony-forming units.

\subsection{Growth Performance}

The effect of acetic acid and sodium bicarbonate on drinking water on growth performance of broiler chickens ( $0-10$ days) is shown in Table 3. T3 decreased body weight and 
feed intake and increased mortality, feed conversion ratio and water intake compared to other treatments $(p<0.05)$. However, both treatments (T1 and T2) did not show statistical differences between them for any measured indicators $(p>0.05)$. Additionally, Figure 1 indicates that the broilers consuming water with sodium bicarbonate showed growth retardation, and at 10 days old, all the slaughtered broilers had ascites (Photo 2), but this was not so for the other experimental treatments.

Table 3. Effect of acetic acid and sodium bicarbonate supplemented to drinking water on growth performance of young broilers ( $0-10$ days).

\begin{tabular}{cccccc}
\hline \multicolumn{7}{c}{ Experimental Treatments } \\
\hline Items & T1 & T2 & T3 & SEM \pm & $p$-Value \\
\hline Body weight (g) & $220.91^{\mathrm{a}}$ & $220.69^{\mathrm{a}}$ & $188.47^{\mathrm{b}}$ & 3.696 & 0.001 \\
Feed intake (g) & $204.75^{\mathrm{a}}$ & $205.33^{\mathrm{a}}$ & $177.95^{\mathrm{b}}$ & 2.775 & 0.001 \\
Feed conversion & $1.16^{\mathrm{b}}$ & $1.17^{\mathrm{b}}$ & $1.24^{\mathrm{a}}$ & 0.015 & 0.012 \\
ratio & $0.65^{\mathrm{b}}$ & $0.65^{\mathrm{b}}$ & $14.47^{\mathrm{a}}$ & 2.653 & 0.007 \\
Mortality (\%) & $557.10^{\mathrm{b}}$ & $531.33^{\mathrm{b}}$ & $843.83^{\mathrm{a}}$ & 31.903 & 0.001 \\
Water intake (ml) &
\end{tabular}

$\mathrm{a}, \mathrm{b}$ Means with different letters in the same row differ at $p<0.05$. SEM: standard error of the mean.

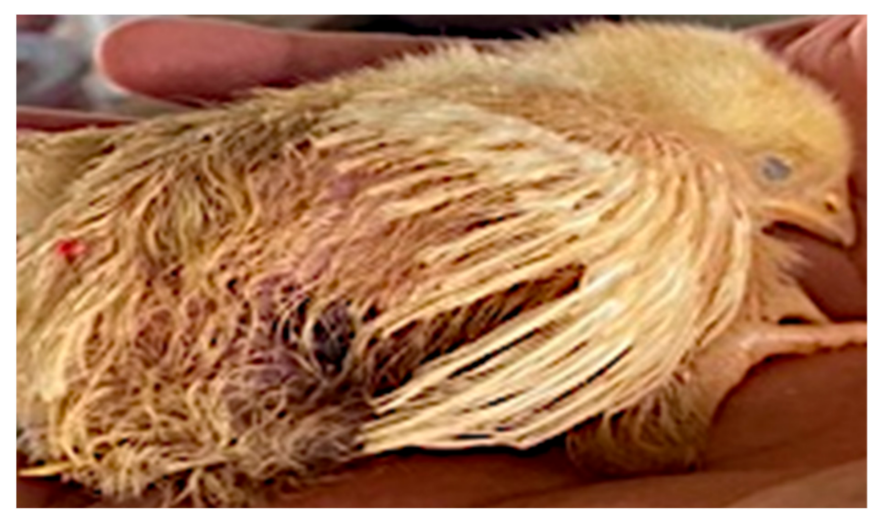

Figure 1. Broiler with growth retardation in T3.

\subsection{Relative Organ Weights, Intestinal pH and Cecal Lactic Acid Bacteria}

The relative weight of the proventriculus, gizzard, small intestine and cecum showed no noticeable differences among treatments $(p>0.05$; Table 4$)$. However, T3 increased $(p<0.05)$ the relative weight of the heart and liver and decreased $(p<0.05)$ the relative weight of the thymus and spleen compared to the other two treatments (Table 4). In addition, this treatment (T3) decreased $(p<0.05)$ the pancreas relative weight in relation to T2. In addition, the relative weight of bursa of Fabricius decreased $(p<0.05)$ due to the acidification (acetic acid, T1) and alkalization (sodium bicarbonate, T3) of the drinking water (T3). Likewise, the Table 4 indicated that T3 increased the cecum $\mathrm{pH}$ with significant differences with the other experimental groups $(p<0.05)$. However, the small intestine $\mathrm{pH}$ and cecal lactic acid bacteria count showed no differences $(p>0.05)$ among treatments.

\subsection{Hemogram}

The results of the hemogram presented in Table 5 showed that the acetic acid and sodium bicarbonate used as acidifying and alkalizing agent, respectively, did not modify $(p>0.05)$ any hematological parameter of young broilers. 
Table 4. Effect of acetic acid and sodium bicarbonate supplemented to drinking water on relative organ weights, intestinal $\mathrm{pH}$ and cecal lactic acid bacteria of young broilers (10 days).

\begin{tabular}{cccccc}
\hline & \multicolumn{7}{c}{ Experimental Treatments } & & \\
\hline Items & T1 & T2 & T3 & SEM \pm & $p$-Value \\
\hline Proventriculus $(\mathrm{g} / \mathrm{kg})$ & 1.53 & 1.11 & 1.06 & 0.291 & 0.466 \\
Gizzard $(\mathrm{g} / \mathrm{kg})$ & 5.65 & 5.92 & 5.21 & 0.320 & 0.303 \\
Small intestine $(\mathrm{g} / \mathrm{kg})$ & 7.34 & 8.07 & 6.95 & 0.431 & 0.196 \\
Small intestine pH & 6.73 & 6.72 & 6.86 & 0.081 & 0.403 \\
Cecum $(\mathrm{g} / \mathrm{kg})$ & 0.91 & 0.91 & 1.10 & 0.089 & 0.241 \\
Cecal $\mathrm{pH}$ & $6.27^{\mathrm{b}}$ & $6.32^{\mathrm{b}}$ & $6.63^{\mathrm{a}}$ & 0.050 & 0.001 \\
Cecal BAL $(\mathrm{CFU} / \mathrm{g})$ & $1.85^{\mathrm{b}}$ & $2.11^{\mathrm{b}}$ & $1.97^{\mathrm{a}}$ & 0.057 & 0.054 \\
Heart $(\mathrm{g} / \mathrm{kg})$ & $0.69^{\mathrm{b}}$ & $0.76^{\mathrm{b}}$ & $0.95^{\mathrm{a}}$ & 0.040 & 0.001 \\
Liver $(\mathrm{g} / \mathrm{kg})$ & $3.29^{\mathrm{b}}$ & $3.48^{\mathrm{b}}$ & $4.27^{\mathrm{a}}$ & 0.177 & 0.001 \\
Pancreas $(\mathrm{g} / \mathrm{kg})$ & $0.54^{\mathrm{ab}}$ & $0.59^{\mathrm{a}}$ & $0.48^{\mathrm{b}}$ & 0.031 & 0.045 \\
Bursa of Fabricius $(\mathrm{g} / \mathrm{kg})$ & $0.17^{\mathrm{b}}$ & $0.22^{\mathrm{a}}$ & $0.19^{\mathrm{b}}$ & 0.018 & 0.009 \\
Thymus $(\mathrm{g} / \mathrm{kg})$ & $0.30^{\mathrm{a}}$ & $0.26^{\mathrm{a}}$ & $0.16^{\mathrm{b}}$ & 0.026 & 0.003 \\
Spleen $(\mathrm{g} / \mathrm{kg})$ & $0.12^{\mathrm{a}}$ & $0.11^{\mathrm{a}}$ & $0.07^{\mathrm{b}}$ & 0.015 & 0.004 \\
\hline
\end{tabular}

$\overline{\mathrm{a}, \mathrm{b}}$ Means with different letters in the same row differ at $p<0.05$. SEM: standard error of the mean. BAL: lactic acid bacteria.

Table 5. Effect of acetic acid and sodium bicarbonate supplemented to drinking water on hematological parameters of young broilers (10 days).

\begin{tabular}{cccccc}
\hline \multicolumn{7}{c}{ Experimental Treatments } \\
\hline Items & T1 & T2 & T3 & SEM \pm & $p$-Value \\
\hline Erythrocytes $(\times 10 \mathrm{~L})$ & 2.60 & 3.01 & 2.71 & 0.184 & 0.335 \\
Hemoglobin (g/dL) & 8.53 & 9.95 & 8.87 & 0.652 & 0.342 \\
CVP (\%) & 26.03 & 30.05 & 27.03 & 1.825 & 0.337 \\
MVC (fL) & 108.13 & 107.70 & 109.60 & 3.899 & 0.938 \\
MCH (pg) & 34.27 & 35.30 & 36.40 & 1.191 & 0.491 \\
PLT (×10 L) & 26.90 & 35.15 & 28.70 & 2.699 & 0.155 \\
Leukocytes(L) & 18,076 & 17050 & 21526 & 263.34 & 0.494 \\
Heterophiles (\%) & 27.33 & 27.50 & 33.67 & 6.164 & 0.723 \\
Eosinophils (\%) & 3.00 & 2.50 & 1.67 & 1.134 & 0.717 \\
Lymphocytes (\%) & 64.67 & 64.50 & 60.00 & 4.951 & 0.761 \\
Monocytes (\%) & 5.00 & 5.50 & 4.67 & 0.788 & 0.763 \\
Basophils (\%) & 0.00 & 0.00 & 0.00 & - & -
\end{tabular}

SEM: standard error of the mean. CVP: central venous pressure; MVC: medium corpuscular volume; MCH: mean corpuscular hemoglobin; PLT: platelets.

\section{Discussion}

One of the goals of this study was to determine whether use of acetic acid as acidifier and sodium bicarbonate as alkalizer in drinking water had an influence on the water quality, which could explain its effect on the biological response of young broilers. In this sense, Vermilion et al. [20] have reported that the immune system benefits from acidic water because it mimics the natural $\mathrm{pH}$ of the crop, though alkaline drinking water weakens humoral immunity and limits the genetic potential of broilers. However, the use of acidifiers and alkalizers in drinking water also has a direct influence on other indicators of water quality. In this sense, the drinking water supplied to broilers should not contain excessive levels of minerals [21]; thus, when the electrical conductivity exceeds $3000 \mu \mathrm{S} / \mathrm{cm}$, it causes a decrease in palatability and an increase in diarrheal syndrome [22]. Based on the results of this study, it is observed that the T1 and T2 did not exceed the aforementioned parameters; however, the $\mathrm{T} 3$ showed $4800 \mu \mathrm{S} / \mathrm{cm}$, much higher than the permissible limit for this indicator (electrical conductivity). Likewise, Oh et al. [23] mentioned that electrical conductivity is an indicator of the degree of mineralization (total ion concentration) of the 
water. Therefore, the electrical conductivity is related to the salinity and concentration of the total dissolved solids.

Moreover, Cobb-Vantress [24] defined that values between 3000 and 4999 ppm of total dissolved solids could engender aqueous feces, increasing mortality rate and slowing down growth. In this study, T3 recorded 3443 ppm, which could directly affect the animal response. Additionally, Aviagen [25] determined that calcium, magnesium and sodium salts are the primary components that contribute to high of TDS, which are pollutants commonly responsible for altering productive performance, specifically increasing mortality rate. This study used $1 \%$ sodium bicarbonate to alkalize the drinking water; thus, an excess level of sodium in feed or water increases blood volume, which requires more cardiac work in broilers; increased blood flow or increased resistance to flow in the lungs results in right ventricular hypertrophy, increased venous pressure and ascites [21]. The relationship between these three parameters (total dissolved solids, salinity and electrical conductivity) was demonstrated in this experiment, where T3 showed a higher concentration of electrical conductivity, total dissolved solids and salinity (Table 2). Therefore, T1 and $\mathrm{T} 2$ are considered adequate for intake, while T3 could slow down the development process of broilers and immune system weaken [21-23].

Furthermore, both treatments that modified the $\mathrm{pH}$ of drinking water (with sodium bicarbonate and acetic acid) totally reduced residual chlorine (Table 2); apparently, changes in the $\mathrm{pH}$ directly influence the self-decomposition of chlorine [26]. In this sense, the World Health Organization [27] informed that chlorination of water is not effective with $\mathrm{pH}$ values higher than 7.2 and lower than 6.8. Thus, this test did not detect residual chlorine in drinking water with a pH of 4.01 and 8.60 (Table 3). Additionally, Len et al. [26] found the total loss of residual chlorine when the water had a pH lower than 2.5 and higher than 9.0. It should be noted that the addition of acetic acid and sodium bicarbonate in the drinking water did not influence the water temperature, turbidity, total coliforms and fecal coliforms (Table 2).

At present, many scientific works have demonstrated the effect of organic acids as acidifiers of drinking water in the production of broilers, although the results are not consistent due to several factors such as the environment, feed palatability, buffer capacity of the diet, concentration of organic acid used, management, gut health, presence of other antimicrobial compounds, water $\mathrm{pH}$ and genetic expression of poultry [28], and many poultry companies continue to frequently use these organic acids (mainly acetic acid) in drinking water, mainly in stressful situations, with the aim of reducing the colonization of intestinal pathogenic bacteria and promoting competitive exclusion [12].

In this sense, Mohammed et al. [29] have shown that the use of acetic acid in drinking water improved the growth performance and the health condition of young broilers. Moreover, Ocampo et al. [30] showed that acidic water in the early stages in broilers reduced the mortality in relation to the control group. Additionally, Ahmad et al. [31] reported positive results on growth performance of broilers with heat stress when they used KCL as an acidifier in drinking water. Furthermore, Chaveerach et al. [32] and Wolfenden et al. [33] concluded that acidified drinking water could prevent the growth of Campylobacter spp. and Salmonella enteritidis in broiler flocks, respectively.

However, in this study, T1 and T2 did not indicate notable differences for the main productive indicators of broilers (Table 3). Similar results were obtained by Martínez et al. [12], who did not find an improvement in performance and viability; these authors concluded that organic acids have a better productive response when broilers are exposed to different challenging conditions. Both treatment (T1 and T2) showed a similar and low mortality (0.65\%; Table 3); perhaps under the experimental conditions of this study, the acidic $\mathrm{pH}$ of the drinking water is not necessary until 10 days.

On the other hand, it is clearly observed that T3 depressed the body weight, feed intake, conversion feed ratio and mortality in $17.09,15.38,5.65$ and $13.82 \%$, respectively, compared to T2 (Table 3; Figure 1). However, Chung et al. [34] indicated contrary results when they used alkaline drinking water (8.05) from magnetization in the initial phase 
of broilers. In this sense, El-Sabrout and Hanafy [35] found that magnetized water had higher concentrations of salinity, total hardness, $\mathrm{Na}^{+}, \mathrm{K}^{-}, \mathrm{Ca}^{2+}, \mathrm{Mg}^{2+}, \mathrm{Cl}_{-}, \mathrm{HCO}_{3}{ }^{-}$and $\mathrm{pH}$ compared to tap water. The aim of water magnetism is that the magnetic field increases the surface tension of the water with an increase in the water $\mathrm{pH}$ and the shear viscosity, which inhibits the formation of scale [36]. Although more reliable studies are needed to understand how magnetized water with an alkaline $\mathrm{pH}$ might be recommended in the poultry industry, it appears that the effect of alkaline $\mathrm{pH}$ in broilers will be mediated by the concentration of electrolytes in the water. According to Sayed and Downing [37], an optimal balance of electrolytes in diet formulation and drinking water for broilers regulate blood and fluid retention. Therefore, excess sodium in the diet or drinking water causes hypernatremia, which increases fluid retention, blood flow, resistance to flow and water consumption for fluid balance [38], a finding found in this study (Table 3).

The results obtained (Table 3) in this study agree with Rojas et al. [39] and Farfán et al. [40] who reported a higher intake of this liquid (water) when using high concentrations of sodium bicarbonate in the drinking water of broilers. In this sense, Olanrewaju et al. [41] stated that the increase in the sodium concentration in water increases the extracellular volume, causing a loss of intracellular water, which is offset by an increase in fluid intake. Additionally, Ahmad et al. [42] found a higher water intake and a better productive response in broilers with heat stress when they used three different sodium salts, namely sodium bicarbonate $\left(\mathrm{NaHCO}_{3}\right)$, sodium carbonate $\left(\mathrm{Na}_{2} \mathrm{CO}_{3}\right)$ and sodium sulphate $\left(\mathrm{Na}_{2} \mathrm{SO}_{4}\right)$, which demonstrates that the vehicle (feed and water) for sodium bicarbonate supplementation will have a direct impact on the animal response. Undoubtedly, the results obtained in this study are a consequence of an increase in electrolyte consumption in broilers.

In this regard, the necropsies performed on broilers (10 days old) that consumed alkaline water due to the use of sodium bicarbonate showed evidence of accumulation of water in the abdominal area (ascites) in $100 \%$ of the animals (Figure 2), which could influence the high mortality recorded in broilers (14\%). The results obtained in this study are supported by Ahmadipour et al. [43], who maintains that high ppm of TDS triggers ascites in broilers. The ascites syndrome is characterized by right congestive heart failure, with generalized hydrostatic venous hypertension, right heart hypertrophy and edema [44]. Currently, improvements in genetics and diet have decreased the incidence of ascites syndrome; however, T3, with an increase in electrical conductivity, total dissolved solids and salinity (Table 2), provoked this pathological condition in broilers [24,25]. It should be noted that this study could contribute to understanding the incidence of ascites syndrome in poultry units that use brackish drinking water from wells, mainly near the coast.

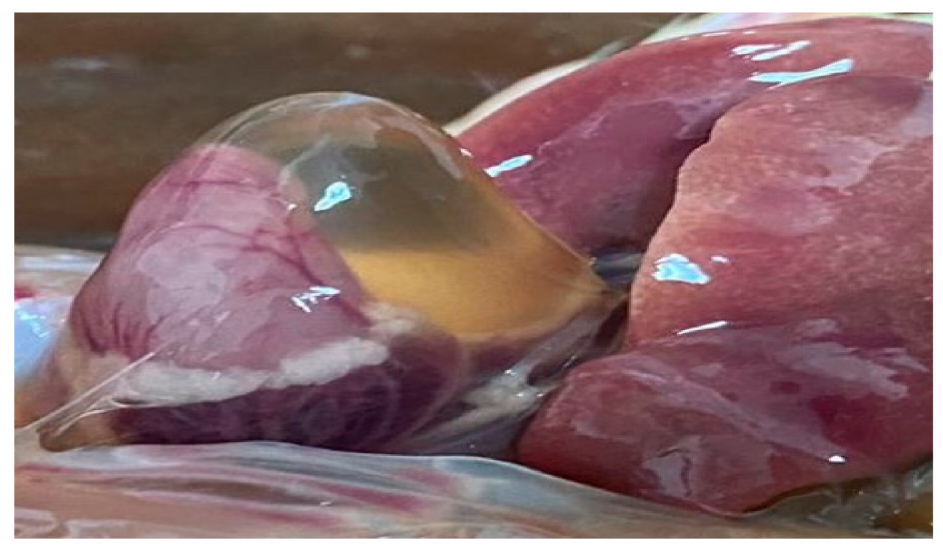

Figure 2. Broiler with ascites in T3.

Interestingly the experimental treatments did not affect the relative weight of the proventriculus, gizzard, small intestine and cecum (Table 4). However, this study showed that the sodium bicarbonate used as an alkalizer also directly affected the relative weight of 
the visceral and immune organs of broilers. In this sense, $\mathrm{T} 3$ increased the relative weight of the heart, liver and pancreas (Table 4) due to ascites syndrome and hypernatremia; thus, one of the most representative symptoms is cardiac hypertrophy [44] due to venous hypertension and intracellular water loss, which provokes higher functionality of the organ. In this sense, Klasing [14] indicated that a sodium concentration higher than $0.04 \%$ (4000 ppm) induces toxicity, ascites syndrome and cardiomegaly, the latter sign caused by cardiac weakening, dilation and hypertrophy. In addition, the intake of electrolytes (mainly sodium) changes the acid-base balance, causing temporary changes in all fluid compartments [45]. Several strategies have been proposed to reduce the incidence of ascites and improve the development of internal organs and animal production, such as early dietary restriction, lower density of diets, restriction of access time to feed and modification of the growth of chickens [46].

In addition, hypernatremia, in this experiment, due to excess $\mathrm{Na}$ in drinking water, could cause hepatomegaly in broilers due to the formation of fibrinous exudate in the blood vessels, which allows the exit of large molecules rich in fibrinogen, forming a fibrin network [47]. In this sense, Martínez et al. [2] found a positive correlation between the relative weight of the heart, liver and spleen due to hepatic portal blood circulation, and between the pancreas and liver due to homeostatic regulation for insulin and glucagon secretion [48], which helps maintain stable glucose levels, which is why these organs were also affected due to the T3. Therefore, this shows that the use of sodium bicarbonate and $\mathrm{pH}$ alkaline in drinking water appears to have three characteristic symptoms: hepatomegaly, cardiomegaly and pancreatomegaly in the first 10 days of life in broilers.

It is important to note that the use of acetic acid and acidic $\mathrm{pH}$ of the drinking water had no effect on the relative weight of these organs (Table 4). In this sense, Abdel-Fattah et al. [49] found no notable changes in relative gizzard weight when lactic, acetic and citric acid were used in broiler diets. However, Martínez et al. [12] found variations in the relative weight of proventriculus, gizzard, small intestine and liver when they used acetic acid in the drinking water of broilers, although the authors found no changes in the relative weight of the cecums. Furthermore, Mohammadi et al. [50] indicated that organic acids statistically modified the relative weight of the liver in broilers. This shows that the relative weight of the digestive organs in apparently healthy animals, as was the case with the T1 and T2, will depend on several intrinsic and extrinsic factors such as the physiological and immunological status of the broilers, age, diet, technology and stressful situations.

Although there are contradictions in the interpretation of the variations in the relative weight of the immune organs and the productive response in broilers, many authors have related better immunological activity with the relative weight of the bursa of Fabricius, thymus and spleen of these animals [51]. It is clearly observed that the T3 depressed the relative weight of these lymphoid organs (Table 4), which could influence the high mortality of this treatment (Table 3); thus, it was observed that the relative weight of the thymus decreased in $0.14 \%$ (Table 4). This organ is taken as an indicator of the bird's health status because it acts in situations of chronic stress, being responsible for the differentiation and development of T lymphocytes [7]. Additionally, interestingly, the bursa of Fabricius, which is the organ responsible for the maturation and differentiation of B lymphocytes [49,52], decreased its relative weight with $\mathrm{T} 1$ and $\mathrm{T} 3$ by 0.05 and $0.02 \%$, respectively (Table 4 ), which could elucidate that both drastic changes in water $\mathrm{pH}$ could reduce the immunological specificity of this organ. However, other experiments are necessary to demonstrate this hypothesis. Additionally, Maxwell et al. [53] informed that ascites syndrome decreases the relative weight and the activity of the bursa of Fabricius due to congestive heart failure. However, Fascina et al. [28] did not record significant differences $(p>0.05)$ in the relative weight of immune organs when they used organic acids and neutral water in broiler production.

One of the main justifications for the use of organic acids, especially acetic acid, in drinking water is that they can lower cecal $\mathrm{pH}$ and reduce the growth of pathogenic bacteria in critical stages and under various stressors in broilers [54]. In this sense, Dibner 
and Butin [55] recommended the use of organic acids to lower intestinal $\mathrm{pH}$, improve nutrient absorption, and decrease the incidence of infections in broilers. In this sense, Hamid et al. [11] showed that ingestion of acidified water lowered the $\mathrm{pH}$ of the gastrointestinal tract and improved productivity in broilers compared to apparently neutral water. Likewise, Martínez et al. [12] showed that the use of organic acids in drinking water decreased the cecal $\mathrm{pH}$ but did not lower the $\mathrm{pH}$ of the small intestine. Likewise, Jaramillo [7] registered a significant decrease in cecal $\mathrm{pH}$ when supplemented with organic acids and antibiotics.

However, our study showed that despite supplying drinking water with a $\mathrm{pH}$ of 4.1 (Table 2), this did not cause a decrease in cecal $\mathrm{pH}$ in broilers (Table 4); similar results were obtained by Abdelrazek et al. [56] when they found no positive results when they used acetic acid in broilers. In this sense, Santos et al. [57] have mentioned that these natural products have a higher effect on the gastrointestinal tract when animals are subjected to stressful conditions. The main contradictions of the effect of organic acids on intestinal $\mathrm{pH}$ are related to the buffering capacity of dietary ingredients, presence of other antimicrobial compounds, heterogeneity of gut microbiota and the production conditions [58,59]. Apparently, the experimental conditions of this study were adequate considering the performance and the cecal $\mathrm{pH}$ of the birds in the groups that consumed apparently neutral and acidic water. Additionally, the diets intentionally did not have growth-promoting antibiotics. On the other hand, it is clearly observed that the significant increase in the cecal $\mathrm{pH}$ of the broilers was due to the alkaline drinking water (Table 4). Rynsburger and Classen [58] argue that high $\mathrm{pH}$ increases protein denaturation and pepsin activity in young broilers, influencing nutrient uptake and animal growth, something that occurred in this experiment (Table 3), as these animals had the worst productive performance.

The cecal microbiota is known to be abundant in lactic acid bacteria such as Lactobacillus, Pediococcus, Oenococcus and Leuconostoc, which directly influence gut health, nutrient absorption and the productive response of broilers [59]. Some authors have related the growth of cecal lactic acid bacteria and the decrease in the $\mathrm{pH}$ of this organ, because it favors competitive exclusion and intestinal health [60]. However, Martínez et al. [12], showed that acetic acid in drinking water reduced the lactic bacteria count due to an excessive decrease in cecal $\mathrm{pH}$, something that did not occur in this experiment, since the $\mathrm{pH}$ remained unchanged when drinking water was supplied with a $\mathrm{pH}$ of 4.01 (Table 4). In this sense, Agboola et al. [61] did not find notable changes in the lactic acid bacteria count in any gut section when they used organic and probiotic acids on broiler diets. Other studies with natural products also found no changes in $\mathrm{pH}$ and cecal lactic acid bacteria in broilers [19], which shows that acetic acid in these apparently healthy broilers has no effect on the total count of cecal lactic acid bacteria. Interestingly, the T3 that caused high mortality and notable changes in the relative weight of the immune and visceral organs (Tables 3 and 4) and the cecal pH of broilers had no effect on the cecal lactic acid bacteria count (Table 4). Although few studies have indicated the effect of sodium bicarbonate on cecal lactic acid bacteria, it appears that the GIT buffer system and its acid-base balance contributed to the cecal $\mathrm{pH}$ being in the normal ranges for young broilers [2], despite the fact that the addition of sodium bicarbonate to drinking water could cause metabolic alkalosis as a consequence of the increase in alkalis in the blood [62]. Furthermore, these results demonstrate that $\mathrm{T} 3$ has a more marked effect on metabolism and immunity than on the cecal microflora of young birds. However, other studies are necessary to verify these hypotheses.

At present, hematological parameters are used as indicators of health in humans and animals. Variations in these indicators can reflect parasitic, fungal, viral and bacterial infections as well as intoxication, dehydration or blood clotting problems [63]. This study showed that although the experimental treatments (mainly T3) changed the growth performance, cecal $\mathrm{pH}$ and the relative weight of some digestive and immune organs (Tables 3 and 4), they did not provoke changes on the hemogram of broilers up to 10 days old (Table 5). Nosrati et al. [64], Nguyen et al. [65] and Gilani et al. [66] found similar results 
when including acidifiers in drinking water and in the feed of broilers; although they found changes in blood biochemistry, performance and gut health, it seems that acidifiers do not induce an abnormal immune response in broilers. Other non-enzymatic natural products can cause changes in polymorphonuclear cells (neutrophils and eosinophils), with the aim of eliminating exogenous material and/or possible toxic and allergenic compounds [67].

On the other hand, alkaline water, possible hypernatremia and ascites syndrome did not cause significant changes in these blood parameters in broilers (Table 5). In this sense, Farfán et al. [40] found no notable differences in hematocrit, hemoglobin, plasma protein, white blood cells and red blood cells when they used sodium bicarbonate, ammonium chloride and sodium chloride treatments in heat stress in broilers to prevent respiratory alkalosis. Additionally, it is important to note that multiple intrinsic and extrinsic factors can cause ascites syndrome in broilers; hypoxia, temperature and the presence of pathogenic bacteria have been described as the most predominant extrinsic causes [68-70]. According to Maxwell et al. [53] the ascites syndrome in young broilers is characterized by an increase in hemoglobin and hematocrit, although heterophilia, monocytosis, lymphocytosis and decreased blood volume are observed depending on the triggering factors. Ascites in broilers caused by hypernatremia is poorly studied; thus, this experiment in young birds (up to 10 days old) may contribute to understanding the effect of other non-infectious etiologies that induce ascites syndrome.

\section{Conclusions}

The use of acetic acid as an acidifier in the drinking water had no effect on the biological response of the young chickens (up to 10 days old) compared to an apparently neutral $\mathrm{pH}$ in the drinking water. However, the use of sodium bicarbonate and therefore an alkaline $\mathrm{pH}$ and high values of salinity, electrical conductivity and dissolved solids in drinking water provoked high mortality, ascites, low productive efficiency, abnormal growth of the heart and liver and low activity of the immune organs, although without effects on the digestive organs, cecal count of lactic acid bacteria and blood count of these animals.

Author Contributions: Conceptualization, Y.M., C.I.A. and C.J.H.; methodology, Y.M., C.I.A., C.J.H. and M.C.A.; software, Y.M., C.I.A., and C.J.H.; validation, Y.M., C.I.A., C.J.H., M.C.A. and A.M.U.; formal analysis, Y.M., C.I.A. and C.J.H.; investigation, Y.M., C.I.A. and C.J.H.; resources, Y.M., M.C.A. and A.M.U.; data curation, Y.M., C.I.A. and C.J.H.; writing-original draft preparation, Y.M., C.I.A. and C.J.H.; writing-review and editing, Y.M., C.I.A., C.J.H., M.C.A., A.M.U. and M.V.; visualization, Y.M., C.I.A. and C.J.H.; supervision, Y.M. and M.C.A.; project administration, Y.M.; funding acquisition, Y.M. All authors have read and agreed to the published version of the manuscript.

Funding: This research received no external funding.

Institutional Review Board Statement: The Science and Agricultural Production Department at Zamorano University, located in San Antonio de Oriente (Honduras), reviewed and approved all the standardized procedures performed in this experiment, which were conducted under the Guidelines for Experimental Animals (Reference number: 20245 and 20193, October 8, 2020).

Informed Consent Statement: Not applicable.

Data Availability Statement: Not applicable.

Conflicts of Interest: The authors declare no conflict of interest.

\section{References}

1. Alkie, T.N.; Yitbarek, A.; Hodgins, D.C.; Kulkarni, R.R.; Taha-Abdelaziz, K.; Sharif, S. Development of innate immunity in chicken embryos and newly hatched chicks: A disease control perspective. Avian Pathol. 2019, 48, 288-310. [CrossRef]

2. Martínez, Y.; Altamirano, E.; Ortega, V.; Paz, P.; Valdivié, M. Effect of age on the immune and visceral organ weights and cecal traits in modern broilers. Animals 2021, 11, 845. [CrossRef]

3. Boyner, M.; Ivarsson, E.; Franko, M.A.; Rezaei, M.; Wall, H. Effect of hatching time on time to first feed intake, organ development, enzymatic activity and growth in broiler chicks hatched on-farm. Animal 2020, 15, 100083. [CrossRef] 
4. Bruno, L.D.G.; Maiorka, A.; Macari, M.; Furlan, R.L.; Givisiez, P.E.N. Water intake behavior of broiler chickens exposed to heat stress and drinking from bell or and nipple drinkers. Braz. J. Poult. Sci. 2011, 13, 147-152. [CrossRef]

5. Do Amaral, L.A. Drinking water as a risk factor to poultry health. Braz. J. Poult. Sci. 2004, 6, 191-199. [CrossRef]

6. $\quad$ Engberg, R.M.; Hedemann, M.S.; Steenfeldt, S.; Jensen, B.B. Influence of whole wheat and xylanase on broiler performance and microbial composition and activity in the digestive tract. Poult. Sci. 2004, 83, 925-938. [CrossRef] [PubMed]

7. Jaramillo, Á.H. Evaluation of a prebiotic and an organic acid-supplemented diets on the performance and allometric parameters of broiler chickens with controlled feeding. Rev. Colomb. Cienc. Pec. 2012, 5, 52-66.

8. Hajati, H. Application of organic acids in poultry nutrition. Int. J. Avian Wildl. Biol. 2018, 3, 324-329. [CrossRef]

9. Bouassi, T.; Libanio, D.; Mesa, M.D.; Oke, O.E.; Gil, A.H.; Tona, K.; Ameyapoh, Y. Supplementation with liquid whey and ACIDAL ${ }^{\circledR}$ ML in drinking water affect gut $\mathrm{pH}$ and microflora and productive performance in laying hens. Brit. Poult. Sci. 2021, 62, 138-146. [CrossRef]

10. Açıköz, Z.; Bayraktar, H.; Altan, Ö. Effects of formic acid administration in the drinking water on performance, intestinal microflora and carcass contamination in male broilers under high ambient temperature. Asian Australas. J. Anim. Sci. 2010, 24, 96-102. [CrossRef]

11. Hamid, H.; Shi, H.Q.; Ma, G.Y.; Fan, Y.; Li, W.X.; Zhao, L.H.; Ma, Q.G. Influence of acidified drinking water on growth performance and gastrointestinal function of broilers. Poult. Sci. 2018, 97, 3601-3609. [CrossRef]

12. Martínez, Y.; González, A.; Perez, K.; Botello, A. Effect of a combination of propionic-acetic acid on body weight, relative weight of some organs, lactic acid bacteria and intestinal pH of neonatal broilers. Braz. J. Poult. Sci. 2021, 23, 1-9. [CrossRef]

13. Watkins, S.E.; Fritts, C.A.; Yan, F.; Wilson, M.L.; Waldroup, P.W. The interaction of sodium chloride levels in poultry drinking water and the diet of broiler chickens. J. Appl. Poult. Res. 2005, 14, 55-59. [CrossRef]

14. Klasing, K.C. Nutritional Diseases. In Diseases of Poultry, 13th ed.; Swayne, D.E., Ed.; John Wiley \& Sons, Inc.: Hoboken, NJ, USA, 2013; pp. 1203-1232.

15. Briggs, W.N.; Duff, A.F.; Chasser, K.M.; Bielke, L.R. Intestinal pioneer colonizers as drivers of ileal microbial composition and diversity of broiler chickens. Front. Microbiol. 2020, 10, 2858.

16. Lee, J.; Sung, Y.K.; Kong, C. Ideal ratios of standardized ileal digestible methionine, threonine, and tryptophan relative to lysine for male broilers at the age of 1 to 10 days. Anim. Feed Sci. Technol. 2020, 262, 114427. [CrossRef]

17. Wilson, K.M.; Rodrigues, D.R.; Briggs, W.N.; Duff, A.F.; Chasser, K.M.; Bielke, L.R. Evaluation of the impact of in ovo administered bacteria on microbiome of chicks through 10 days of age. Poult. Sci. 2019, 98, 5949-5960. [CrossRef]

18. Cobb-Vantress. Broiler Performance \& Nutrition Supplement. 2018. Available online: https://www.cobb-vantress.com/assets/ Cobb-Files/product-guides/bdc20a5443/70dec630-0abf-11e9-9c88-c51e407c53ab.pdf (accessed on 10 September 2020).

19. Molina, D.S.; Bernardo, J.; Machado, O.D.; Más, D.; Martínez, Y. Nutraceutical effect of Ganoderma lucidum fungus on neonatal broilers diet. Int. J. Poult. Sci. 2019, 18, 641-647. [CrossRef]

20. Vermilion, B.; Muthuvel, S.; Govidasamy, P.; Villavan, M.; Alagawany, M.; Ragab, M.; Dhama, K.; Gopi, M. Roles of acidifiers in livestock nutrition and health. J. Anim. Physio. Anim. Nutr. 2020, 104, 558-569.

21. Julian, R.J. The effect of increased sodium in the drinking water on right ventricular hypertrophy, right ventricular failure and ascites in broiler chickens. Avian Pathol. 1987, 16, 61-71. [CrossRef]

22. Abbas, T.E.; Elzubeir, E.A.; Arabbi, O.H. Drinking water quality and its effects on broiler chicks performance during winter season. Int. J. Poult. Sci. 2008, 7, 433-436. [CrossRef]

23. Oh, J.; Jung, D.; Oh, S.H.; Roh, K.; Ga, S.; Lee, J.H. Design, simulation and feasibility study of a combined $\mathrm{CO}_{2}$ mineralization and brackish water desalination process. J. CO2 Util. 2019, 34, 446-464. [CrossRef]

24. Cobb-Vantress. Broiler Management Guide. 2013. Available online: http:/ / www.tt-trade.cz/docs/cobb-broiler-en.pdf (accessed on 16 May 2020).

25. Ross Broiler Management Handbook. 2018. Available online: https://en.aviagen.com/assets/Tech_Center/Ross_Broiler/RossBroilerHandbook2018-EN.pdf (accessed on 22 June 2020).

26. Len, S.V.; Hung, Y.C.; Chung, D.; Anderson, J.L.; Erickson, M.C.; Morita, K. Effects of storage conditions and pH on chlorine loss in electrolyzed oxidizing (EO) water. J. Agric. Food Chem. 2002, 50, 209-212. [CrossRef] [PubMed]

27. World Health Organization. Measuring Chlorine Levels in Water Supplied. 2005. Available online: https://www.who.int/water_ sanitation_health/publications/2011/tn11_chlorine_levels_en.pdf?ua=1 (accessed on 20 May 2020).

28. Fascina, V.B.; Pasquali, G.A.M.; Carvalho, F.B.; Muro, E.M.; Vercese, F.; Aoyagi, M.M.; Pezzato, A.C.; Gonzales, E.; Sartori, J.R. Effects of phytogenic additives and organic acids, alone or in combination, on the performance, intestinal quality and immune responses of broiler chickens. Braz. J. Poult. Sci. 2017, 19, 497-508. [CrossRef]

29. Mohammed, H.A. Effect of organic acids supplanted in drinking water during pre-starter and starter feeding phase on broiler performance. Polytech. J. 2018, 8, 60-69. [CrossRef]

30. Ocampo, C.L.; Gómez-Verduzco, G.; Tapia-Perez, G.; Gutierrez, O.L.; Sumano, L.H. Effects of Glycyrrhizic acid on productive and immune parameters of broilers. Braz. J. Poult. Sci. 2016, 18, 435-442. [CrossRef]

31. Ahmad, T.; Khalid, T.; Mushtaq, T.; Mirza, M.A.; Nadeem, A.; Babar, M.E.; Ahmad, G. Effect of potassium chloride supplementation in drinking water on broiler performance under heat stress conditions. Poult. Sci. 2008, 87, 1276-1280. [CrossRef] 
32. Chaveerach, P.; Keuzenkamp, D.A.; Lipman, L.J.A.; Van-Knapen, F. Effect of organic acids in drinking water for young broilers on Campylobacter infection, volatile fatty acid production, gut microflora and histological cell changes. Poult. Sci. 2004, 83, 330-334. [CrossRef] [PubMed]

33. Wolfenden, A.D.; Vicente, J.L.; Higgins, J.P.; Andreatti, R.L.; Higgins, S.E.; Hargis, B.M.; Tellez, G. Effect of organic acids and probiotics on Salmonella enteritidis infection in broiler chickens. Int. J. Poult. Sci. 2002, 6, 403-405. [CrossRef]

34. Chung, E.L.; Nayan, N.; Hamidi Kamalludin, M.; Alghirani, M.M.; Abdullah Jesse, F.F.; Kassim, N.A.; Azizi, A.; Hanif Reduan, M.F.; Loh, T.C. The effects of alkaline water and rainwater on the production and health performance of commercial broilers under tropical conditions. Thai J. Vet. Med. 2020, 50, 53-61.

35. El-Sabrout, K.; Hanafy, M. Effect of magnetized water on productive traits of laying chickens. Prof. Anim. Sci. 2017, 33, 739-742. [CrossRef]

36. Esmaeilnezhad, E.; Choi, H.J.; Schaffie, M.; Gholizadeh, M.; Ranjbar, M. Characteristics and applications of magnetized water as a green technology. J. Clean. Prod. 2017, 161, 908-921. [CrossRef]

37. Sayed, M.A.M.; Downing, J. Effects of dietary electrolyte balance and addition of electrolyte-betaine supplements in feed or water on performance, acid-base balance and water retention in heat-stressed broilers. Br. Poult. Sci. 2015, 56, 195-209. [CrossRef]

38. Hayat, J.; Balnave, D.; Brake, J. Sodium bicarbonate and potassium bicarbonate supplements for broilers can cause poor performance at high temperatures. Br. Poult. Sci. 2010, 40, 411-418. [CrossRef]

39. Rojas, J.; Comerma, S.; Chacón, T.; Rossini, M.; Zerpa, H.; Farfán, C.; Vasco, B. Effect of the addition of minerals in water or food on heart rate, on broiler chickens subjected to chronic and acute caloric stress. J. Fac. Vet. Sci. 2008, 49, 99-111.

40. Farfán, C.; Oliveros, Y.; De Basilio, V. Effect of the addition of minerals in water or food on productive and physiological variables in broiler chickens under caloric stress. Zootec. Trop. 2010, 28, 363-373.

41. Olanrewaju, H.A.; Thaxton, J.P.; Dozier, W.A.; Branton, S.L. Electrolyte diets, stress, and acid-base balance in broiler chickens Poult. Sci. 2007, 86, 1363-1371. [CrossRef] [PubMed]

42. Ahmad, T.; Mushtaq, T.; Mahr-Un-Nisa, M.; Hooge, D.M.; Mirza, M.A. Effect of different non-chloride sodium sources on the performance of heat-stressed broiler chickens. Brit. Poult. Sci. 2006, 47, 249-256. [CrossRef] [PubMed]

43. Ahmadipour, B.; Kalantar, M.; Schreurs, N.M.; Raza, S.H.A.; Khan, R.; Khan, S.; Abd El-Aziz, A.H.; Memon, S.; Ullah, I.; Samira, A Flavonoid bioactive compounds of hawthorn extract can promote growth, regulate electrocardiogram waves, and improve cardiac parameters of pulmonary hypertensive chickens. Poult. Sci. 2020, 99, 974-980. [CrossRef]

44. Baghbanzadeh, A.; Decuypere, E. Ascites syndrome in broilers: Physiological and nutritional perspectives. Avian Pathol. 2008, 37, 117-126. [CrossRef] [PubMed]

45. Macalintal, L.M.; Pescatore, A.J.; Ao, T.; Ford, M.J.; Dawson, K.A. Organic minerals restore the acid-base and electrolyte balance in broiler chicks with nutritionally induced metabolic acidosis. J. Appl. Anim. Nutr. 2020, 8, 41-48. [CrossRef]

46. Mohammadalipour, R.; Rahmani, H.R.; Jahanian, R.; Riasi, A. Effect of early feed restriction on physiological responses, performance and ascites incidence in broiler chickens raised in normal or cold environment. Animal 2017, 11, 219-226. [CrossRef]

47. Tottori, J.; Yamaguchi, R.; Murakawa, Y.; Sato, M.; Uchida, K.; Tateyama, S. Experimental production of ascites in broiler chickens using infectious bronchitis virus and Escherichia coli. Avian Dis. 1997, 41, 214-220. [CrossRef] [PubMed]

48. Seki, Y.; Sato, K.; Kono, T.; Abe, H.; Akiba, Y. Broiler chickens (Ross strain) lack insulin-responsive glucose transporter GLUT4 and have GLUT8 cDNA. Gen. Comp. Endocrinol. 2003, 133, 80-87. [CrossRef]

49. Abdel-Fattah, S.A.; El-Sanhoury, M.H.; El-Mednay, N.M.; Abdel, A.F. Thyroid activity, some blood constituents, organs morphology and performance of broiler chicks fed supplemental organic acids. Int. J. Poult. Sci. 2008, 7, 215-222. [CrossRef]

50. Mohammadi, G.M.; Hosseindoust, A.; Kim, I.H. Evaluating the effect of microencapsulated blends of organic acids and essential oils in broiler chicken diet. J. Appl. Poult. Res. 2015, 24, 511-519. [CrossRef]

51. Perozo, F.; Nava, J.; Mavárez, Y.; Arenas, E.; Serje, P.; Briceño, M. Morphometric characterization of Ross line broiler chickens lymphoid organs reared under field conditions in Zulia state. Rev. Cient. Fac. Cienc. Vet. 2004, 14, 1-18.

52. Hirakawa, R.; Nurjanah, S.; Furukawa, K.; Murai, A.; Kikusato, M.; Nochi, T.; Toyomizu, M. Heat stress causes immune abnormalities via massive damage to effect proliferation and differentiation of lymphocytes in broiler chickens. Front. Vet. Sci. 2020, 7, 46. [CrossRef]

53. Maxwell, M.H.; Robertson, G.W.; Spence, S. Studies on an ascitic syndrome in young broilers 1. haematology and pathology. Avian Pathol. 1986, 15, 511-524. [CrossRef]

54. Kammon, A.; Alzentani, S.; Tarhuni, O.; Asheg, A. Effect of some organic acids on body weight, immunity and cecal bacterial count of chicken during heat stress. Int. J. Poult. Sci. 2019, 10, 293-300. [CrossRef]

55. Dibner, J.; Buttin, P. Use of organic acids as a model to study the impact of gut microflora on nutrition and metabolism. J. Appl. Poult. Res. 2002, 11, 453-463. [CrossRef]

56. Abdelrazek, H.M.A.; Abuzead, S.M.M.; Ali, S.A.; El-Genaidy, H.M.A.; Abdel-Hafez, S.A. Effect of citric and acetic acid water acidification on broiler's performance with respect to thyroid hormones levels. Adv. Anim. Vet. Sci. 2016, 4, 271-278. [CrossRef]

57. Santos, R.R.; Awati, A.; Roubos-Van den Hil, P.J.; Van Kempen, T.A.; Tersteeg-Zijderveld, M.H.; Koolmees, P.A.; Fink-Gremmels, J. Effects of a feed additive blend on broilers challenged with heat stress. Avian Pathol. 2019, 48, 582-601. [CrossRef]

58. Rynsburger, M.; Classen, H.L. Effect of age on intestinal $\mathrm{pH}$ of broiler chickens. Proc. Int. Poult. Sci. Forum. Poult. Sci. 2007, 86 (Suppl. S1), 724. 
59. Bjerrum, L.; Engberg, R.M.; Leser, T.D.; Jensen, B.B.; Finster, K.; Pedersen, K. Microbial community composition of the ileum and cecum of broiler chickens as revealed by molecular and culture-based techniques. Poult. Sci. 2006, 85, 1151-1164. [CrossRef] [PubMed]

60. Tellez, G.; Dean, C.E.; Corrier, D.E.; Deloach, J.R.; Jaeger, L.; Hargis, B.M. Effect of dietary lactose on cecal morphology, pH, organic acids, and Salmonella enteritidis organ invasion in Leghorn chicks. Poult. Sci. 1993, 72, 636-642. [CrossRef] [PubMed]

61. Agboola, A.F.; Omidiwura, B.R.O.; Odu, O.; Popoola, I.O.; Iyayi, E.A. Effects of organic acid and probiotic on performance and gut morphology in broiler chickens. S. Afr. J. Anim. Sci. 2015, 45, 494-501. [CrossRef]

62. Borges, S.A.; Da Silva, A.F.; Majorka, A.; Hooge, D.M.; Cummings, K.R. Physiological responses of broiler chickens to heat stress and dietary electrolyte balance (sodium plus potassium minus chloride, milliequivalents per kilogram). Poult. Sci. 2004, 83, 1551-1558. [CrossRef]

63. Talebi, A.; Asri-Rezaei, S.; Rozeh-Chai, R.; Sahraei, R. Comparative studies on haematological values of broiler strains (Ross, Cobb, Arbor-acres and Arian). Int. J. Poult. Sci. 2005, 4, 573-579.

64. Nosrati, M.; Javandel, F.; Camacho, L.M.; Khusro, A.; Cipriano, M.; Seidavi, A.; Salem, A.Z.M. The effects of antibiotic, probiotic, organic acid, vitamin C, and Echinacea purpurea extract on performance, carcass characteristics, blood chemistry, microbiota, and immunity of broiler chickens. J. Appl. Poult. Res. 2017, 26, 295-306. [CrossRef]

65. Nguyen, D.H.; Lee, K.Y.; Mohammadigheisar, M.; Kim, I.H. Evaluation of the blend of organic acids and medium-chain fatty acids in matrix coating as antibiotic growth promoter alternative on growth performance, nutrient digestibility, blood profiles, excreta microflora, and carcass quality in broilers. Poult. Sci. 2018, 97, 4351-4358. [CrossRef]

66. Gilani, S.M.H.; Zehra, S.; Galani, S.; Ashraf, A. Effect of natural growth promoters on immunity, and biochemical and haematological parameters of broiler chickens. Trop. J. Pharm. Res. 2018, 17, 627-633. [CrossRef]

67. Attia, Y.A.; Al-Harthi, M.A. Nigella seed oil as an alternative to antibiotic growth promoters for broiler chickens. Europ. Poult. Sci. 2015, 79, 10-1399.

68. Boostani, A.; Ashayerizadeh, A.; Mahmoodian, F.H.; Kamalzadeh, A. Comparison of the effects of several feed restriction periods to control ascites on performance, carcass characteristics and hematological indices of broiler chickens. Braz. J. Poult. Sci. 2010, 12, 170-177. [CrossRef]

69. Varmaghany, S.; Rahimi, S.; Torshizi, M.K.; Lotfollahian, H.; Hassanzadeh, M. Effect of olive leaves on ascites incidence, hematological parameters and growth performance in broilers reared under standard and cold temperature conditions. Anim. Feed Sci. Technol. 2013, 185, 60-69. [CrossRef]

70. Scheele, C.W.; Van, J.D.; Kwakernaak, C.; Buys, N.; Decuypere, E. Haematological characteristics predicting susceptibility for ascites. 2. High haematocrit values in juvenile chickens. Brit. Poult. Sci. 2003, 44, 484-489. [CrossRef] [PubMed] 